\title{
Effect and impact of mechanical ventilation in myotonic dystrophy type 1 : a prospective cohort study
}

\author{
Ghilas Boussaïd, 1,2,3 Hélène Prigent, ${ }_{1}^{3,4}$ Pascal Laforet, ${ }^{5}$ Jean-Claude Raphaël, ${ }^{6}$ \\ Djillali Annane, ${ }^{1,3,6}$ David Orlikowski, ${ }^{1,3,6}$ Frédéric Lofaso ${ }^{2,3,4}$
}

- Additional material is published online only. To view please visit the journal online (http://dx.doi.org/10.1136/ thoraxjnl-2017-210610).

${ }^{1}$ CIC 1429, INSERM, AP-HP, Hôpital Raymond Poincaré, Garches, France

${ }^{2}$ Association Française contre les Myopathies-Téléthon, Évry, France

${ }^{3}$ Université de Versailles SaintQuentin-en-Yvelines, INSERM U1179, Versailles, France

${ }^{4}$ Service d'Explorations Fonctionnelles Respiratoires, APHP, Hôpital Raymond Poincaré, Garches, France

${ }^{5}$ Institut de Myologie, Centre de Référence de Pathologie Neuromusculaire Paris-Est, GH Pitié-Salpêtrière, Paris, France ${ }^{6}$ Pôle de ventilation à domicile AP-HP, Hôpital Raymond Poincaré, Garches, France

Correspondence to Ghilas Boussaïd, Centre Investigation Clinique 1429, CHU-Hôpital Raymond Poincaré, 104 Boulevard Raymond Poincaré, 92380 Garches, France; boussaid.gh@gmail.com

Received 8 June 2017 Revised 25 January 2018 Accepted 29 January 2018 Published Online First 23 March 2018

\section{Check for updates}

To cite: Boussaïd $\mathrm{G}$ Prigent $\mathrm{H}$, Laforet $\mathrm{P}$, et al.

Thorax 2018;73:1075-1078.

\section{ABSTRACT}

Few studies have assessed the impact of home ventilation in patients with myotonic dystrophy type 1 (DM1) and no specific recommendations are available. We assessed the survival associated with category of home ventilation adherence of patients with DM1 followed up at a home ventilation unit using a Cox proportional hazards model. 218 patients were included; those who refused or delayed their acceptance of noninvasive ventilation were at higher risk for severe events (invasive ventilation or death) ( $P=0.03)$. Risk of death was associated with orthopnoea (HR 2.37; 95\% Cl 1.17 to 4.80; $P<0.02$ ) and adherence category (100 to $90 \%$ vs $>75 \%$ : HR 3.26; $95 \% \mathrm{Cl} 1.32$ to $8.04 ; \mathrm{P}<0.03$ ). Failure to use home ventilation as prescribed may be associated with increased mortality in patients with DM1.

\section{INTRODUCTION}

Myotonic dystrophy type 1 (DM1) is the most common type of adult muscular dystrophy, ${ }^{1}$ where respiratory failure has been reported as the leading cause of death. ${ }^{2}$ Although many patients with DM1 require home ventilation, ${ }^{3}$ few studies have evaluated the impact of it and no specific recommendations are available.

Randomised trials are required in patients with DM1 to assess the long-term beneficial effects of mechanical ventilation on quality of life, morbidity and mortality, and to estimate the cost-benefit ratio. ${ }^{4}$ However, poor adherence to treatment has been reported in patients with $\mathrm{DM} 1^{56}$ which may be a major barrier to conducting randomised trials.

Here, we report a prospective cohort study in which we compared survival in patients who accepted non-invasive ventilation (NIV) promptly and in those who refused or delayed NIV. In NIV users, we explored for associations between adherence to the prescribed NIV and outcomes.

\section{POPULATION AND METHODS}

The study was approved by the French Data Protection Authority in accordance with French legislation. Patients were informed about the study and could decline to have their data used for the study.

\section{Population}

DM1 adults meeting the criteria for NIV as part of their usual follow-up at the home ventilation unit of the Raymond Poincaré University Hospital
(Garches, France) between 1997 and 2013 were eligible for the study (for more details, see online supplementary annex 1 in the online repository). All patients were receiving pressure support with positive end-expiratory pressure (PEEP) via bilevel positive airway pressure or a similar modality. Autoadjusting CPAP was used first to titrate the level of PEEP, as described by Sanders and Kern. ${ }^{7}$ The level of pressure support was then adjusted to avoid hypercapnia.

\section{Data collection}

Data were collected prospectively during the first respiratory function evaluation, then during the annual follow-up evaluations, for 10 years or until death or lost to follow-up.

The criteria for NIV initiation were systematically researched ${ }^{8}$ : symptoms suggestive of hypercapnia (dyspnoea at rest and on exertion, morning headaches, orthopnoea, sleep disturbances, diurnal sleepiness); combined with alveolar hypoventilation $\left(\mathrm{PaCO}_{2} \geq 45 \mathrm{~mm} \mathrm{Hg}\right)$ or nocturnal arterial oxygen desaturation by pulse oximetry ( $\mathrm{SpO} 2 \leq 88 \%$ for five consecutive minutes), or restrictive lung disease (vital capacity (VC) $<50 \%$ of predicted).

In addition, data on prescribed NIV duration (hours/day) and mean NIV duration/day were obtained. Adherence to the NIV regimen was defined as the ratio of actual NIV time used over prescribed NIV time, expressed as a percentage, which was used to define three adherence categories $(<75 \%, 75 \%-90 \%$ and $>90 \%)$. Patients who started NIV within 1 year after meeting the criteria were classified in the early NIV (eNIV) group and patients who started NIV later on or not at all were classified in the late/no NIV (l/noNIV) group.

\section{Statistical analysis}

Respiratory parameters associated with peak cough flow (PCF) value were identified using multivariate linear regression analysis. The multivariate model was adjusted for gender, age at baseline and a selection of factors associated with $\mathrm{P}$ values $<0.15$ in the univariate analysis and identified by stepwise forward selection. Q-Q plots of the residuals, residuals versus fitted values and residuals versus leverage were used to test the linearity assumptions.

Kaplan-Meier curves were plotted to evaluate the time to occurrence of death or invasive mechanical ventilation (IMV) according to NIV group (eNIV or 1/noNIV or ventilated).

Survival was calculated from the date of 
ventilation initiation to the date of death from any cause. A Cox proportional hazards model was used to estimate HRs for death associated with NIV adherence category (<75\%, 75\%-90\% and $>90 \%$ ) after adjustment for risk factors. The proportional HR assumption was tested based on Schoenfeld residuals.

Statistical significance was set at 0.05 (two-tailed test). Analyses were carried out with SAS software V.9.4 for Windows (SAS Institute) and R software V.2.2.0 (https://www.r-project.org/).

\section{RESULTS}

\section{Patient characteristics at baseline}

From 1997 to 2013, up to 218 patients (128 men, 59\%) with a mean age of $44 \pm 2.1$ years were studied. Twenty-eight (13\%) were already using mechanical ventilation on the first visit. Among the 190 (87\%) patients who required NIV, 72 (38\%) were in the eNIV group and $118(62 \%)$ were in the $1 /$ noNIV group; of the latter, 27 (23\%) accepted NIV after more than 1 year and 91 (77\%) never accepted NIV. Of the 91 patients who did not accept NIV, 17 (19\%) required tracheostomy.

Lung function impairment was significantly greater in the $1 /$ noNIV group than in the eNIV group. Of the $118 \mathrm{l} /$ noNIV group patients, $36 \%$ had VC $<50 \%$ of predicted and $92 \%$ had $\mathrm{PaCO}_{2}$ $>45 \mathrm{~mm} \mathrm{Hg}$ compared with $19 \%$ and $72 \%$, respectively, in the eNIV group $(\mathrm{P}<0.01$ and $\mathrm{P}<0.03$, respectively) (for details, see online supplementary table $\mathrm{R} 1$ in the online repository).

Mean maximum inspiratory pressure (MIP) was 53\% $\pm 23 \%$ of predicted in this population. PCF was lower than $270 \mathrm{~L} / \mathrm{min}$ in $40(14 \%)$ patients, including $15(5 \%)$ with PCF values lower than $180 \mathrm{~L} / \mathrm{min}$.

By stepwise linear regression analysis, greater PCF impairment was associated with lower values of MIP $(\mathrm{P}=0.005)$, maximum expiratory pressure $(\mathrm{P}=0.02)$, expiratory reserve volume $(\mathrm{P}=0.0003)$ and inspiratory capacity $(\mathrm{P}<0.0001)$.

\section{Mortality in patients meeting the criteria for NIV}

During a follow-up period of 959 patient-years, 53 patients reached the endpoint with an annual rate of 53/959 (6\%) and a 10-year cumulative incidence of 53/218 (24\%). Mean follow-up was $4.4 \pm 3.8$ years. Death was due to cardiac causes in $3(6 \%)$, respiratory causes in $24(45 \%)$, cancer in $2(4 \%)$ and unknown causes in
$24(45 \%)$ patients. Mean age at death was 58.2 \pm 8.7 years.

The risk of a severe event (IMV or death) was significantly higher in the 1/noNIV group than in the eNIV group and ventilated group $(\mathrm{P}=0.03)$ (figure 1$)$.

\section{Adherence to prescribed NIV duration among NIV users}

Of the 127 patients who used NIV, the 10 -year survival was $71 \%$ (53/75 patients with follow-up data). The initially prescribed NIV time was $\leq 10$ hours/day in $106(83 \%)$ patients and $\geq 12$ hours/ day in $23(18 \%)$ patients, including one prescribed continuous NIV. Of the 105 patients prescribed 8 hours/day of NIV, 30 (24\%) used NIV for less than 4 hours/day, including 17 (13\%) who never used NIV. Of the 23 patients prescribed $\geq 12$ hours/ day of NIV, only one used NIV for less than 6 hours/day.

Two factors were independently and significantly associated with death: orthopnoea (HR 2.37; 95\% CI 1.17 to 4.80; $\mathrm{P}<0.02)$ and category of adherence to the prescribed NIV duration $(100$ to $90 \%$ vs $>75 \%$ : HR $3.26 ; 95 \%$ CI 1.32 to 8.04 ; $\mathrm{P}<0.03$ ) (table 1).

In the $1 /$ noNIV group, two factors were independently and significantly associated with death: PCF $(\mathrm{P}<0.03)$ and older age at NIV prescription $(\mathrm{P}<0.001)$ (online supplementary table $\mathrm{R} 1$ in the online repository).

\section{DISCUSSION}

Of the patients with DM1 who met the criteria for starting NIV, two-thirds failed to start NIV within 1 year of prescription and were at higher risk for death or IMV compared with those who started NIV within 1 year of NIV prescription. Finally, among NIV users, those with poor adherence to the prescribed duration of NIV use had a significantly higher risk of death.

In DM1, respiratory failure is a multifactorial process related to respiratory muscle weakness, myotonia, breathing dysregulation, sleep-related breathing disorders and cough impairment. Alveolar hypoventilation is common and may require ventilatory assistance. In addition, impaired airway secretion clearance can promote the development of acute respiratory failure. Furthermore, quality of life considerations may limit the ability of patients with DM1 to adhere to recommendations regarding ventilator assistance and other treatments. ${ }^{9}$ Poor adherence to

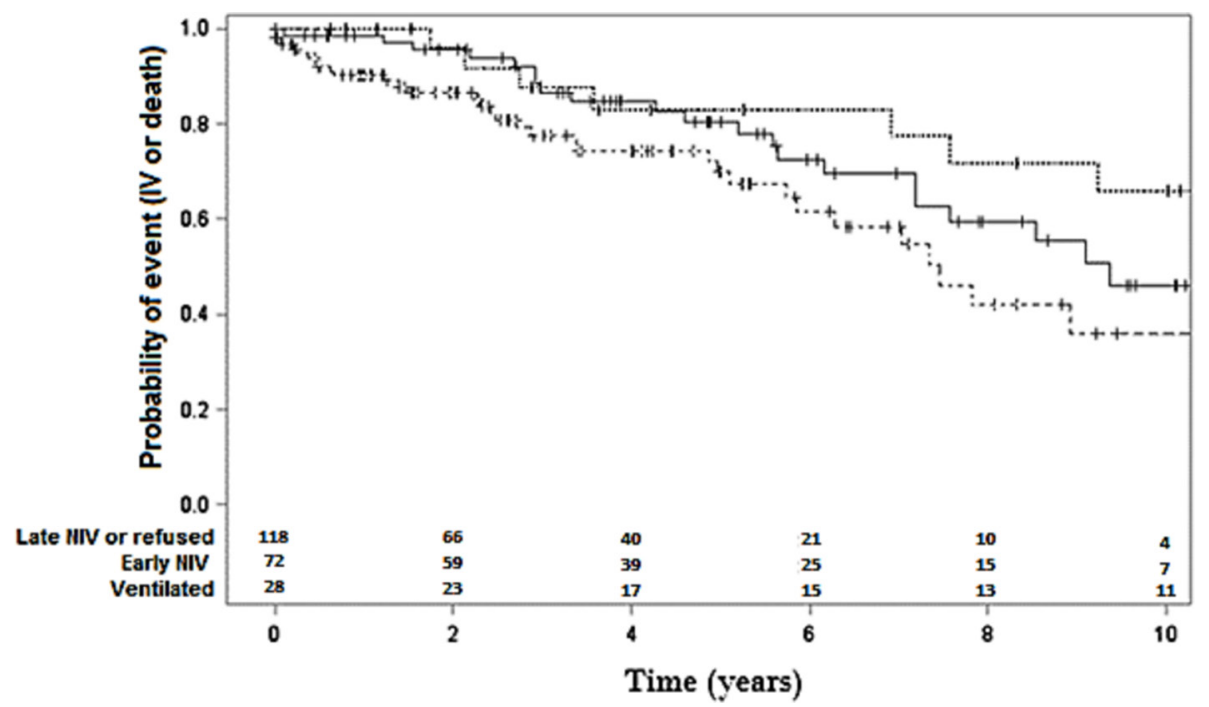

Figure 1 Mortality in patients meeting the criteria for non-invasive ventilation (NIV). NIV users: time to death or invasive mechanical ventilation in patients who accepted NIV within 1 year (early NIV (eNIV) group), accepted NIV later on or not at all (late/no NIV (I/noNIV) group), or were already using mechanical ventilation at baseline. 
Table 1 Cox model: predictors of 10-year mortality among users of NIV $(n=127)$

\begin{tabular}{|c|c|c|c|c|}
\hline \multirow[b]{2}{*}{ Variables } & \multicolumn{2}{|l|}{ Univariate model } & \multicolumn{2}{|l|}{ Multivariate model } \\
\hline & $\mathrm{HR}(95 \% \mathrm{Cl})$ & $P$ value & $\mathrm{HR}(95 \% \mathrm{Cl})$ & $P$ value \\
\hline \multicolumn{5}{|c|}{ NIV adherence (\% of prescribed duration)* } \\
\hline $100-90$ & $1 \dagger$ & & $1 \dagger$ & \\
\hline $90-75$ & $1.45(0.63$ to 3.35$)$ & 0.15 & 2.81 (1.08 to 7.28$)$ & 0.03 \\
\hline$\geq 75$ & 2.05 (0.90 to 4.68$)$ & & 3.26 (1.32 to 8.04$)$ & \\
\hline \multicolumn{5}{|l|}{ Age at DM1 diagnosis } \\
\hline$<20$ & $1 \dagger$ & & $1 \dagger$ & \\
\hline $20-30$ & $1.86(0.65$ to 5.30$)$ & 0.05 & 1.64 (0.56 to 4.79$)$ & 0.10 \\
\hline $30-40$ & $1.96(0.57$ to 6.70$)$ & & 1.39 (0.39 to 4.88$)$ & \\
\hline$>40$ & 3.33 (1.38 to 8.05$)$ & & $3.13(1.21$ to 8.10$)$ & \\
\hline Able to walk $†$ & 0.44 (0.18 to 1.07$)$ & 0.07 & $0.44(0.16$ to 1.20$)$ & 0.11 \\
\hline \multicolumn{5}{|c|}{ Symptoms of respiratory failure } \\
\hline Dyspnoea at rest & $0.40(0.05$ to 2.90$)$ & 0.38 & - & - \\
\hline Exertional dyspnoea & $0.79(0.40$ to 1.58$)$ & 0.72 & - & - \\
\hline Morning headaches & $1.05(0.52$ to 2.12$)$ & 0.45 & - & - \\
\hline Orthopnoea & 2.50 (1.29 to 4.87$)$ & 0.007 & 2.37 (1.17 to 4.80$)$ & 0.02 \\
\hline Sleep disturbances & $1.03(0.53$ to 2.01$)$ & 0.81 & - & - \\
\hline Diurnal sleepiness & 1.30 (0.59 to 2.86$)$ & 0.51 & - & - \\
\hline \multicolumn{5}{|l|}{ VC (\%) } \\
\hline$\geq 50$ & $1 \dagger$ & 0.13 & - & 0.28 \\
\hline $30-50$ & 1.70 (0.76 to 3.77$)$ & & $0.31(0.05$ to 1.85$)$ & \\
\hline$\leq 30$ & $3.71(0.98$ to 14.09$)$ & & $1.34(0.52$ to 3.50$)$ & \\
\hline Pacemaker (yest) & $1.10(0.21$ to 4.38$)$ & 0.89 & - & - \\
\hline $\mathrm{PaCO}_{2} \geq 45 \mathrm{~mm} \mathrm{Hg}$ & $1.26(0.49$ to 3.20$)$ & 0.63 & - & - \\
\hline
\end{tabular}

$P$ value significant are bold values.

* NIV adherence was computed as the ratio of NIV duration in hours/day over prescribed NIV duration in hours/day.

tIndicates the reference category.

DM1, myotonic dystrophy type 1 ; NIV, non-invasive ventilation; VC, vital capacity calculated as the percentage of predicted ( $\geq 50$, normal; 30-50, restrictive syndrome; $\leq 30$,

severe restrictive syndrome).

NIV may be related to the patient, family and caretakers, and/or equipment (ventilator and interface).

Oddly enough, patients who were reluctant to start NIV had more advanced disease. The progression of DM1 is often marked by cognitive dysfunction, ${ }^{10}$ which may influence adherence to NIV treatment, the risk of NIV-related complications and symptom control. Furthermore, a study has shown low sensitivity to hypercapnia among patients with DM1. ${ }^{11}$ Interestingly, a recent study showed no clinical deterioration 1 month after NIV withdrawal in patients with DM1. ${ }^{12}$ This finding does not contradict our results, as the NIV duration used to classify our patients as eNIV or 1/noNIV groups was 1 year.

\section{LIMITATIONS}

Because of the observational design, duration of participation varied across patients, and patient attrition was high. Nevertheless, the percentage of patients lost to follow-up did not differ significantly between the eNIV and 1/noNIV groups (61\% vs 68\%, respectively) and was taken into account in the Kaplan-Meier analysis assuming that censorship is non-informative (ie, that the censorship is independent of death or IMV) ${ }^{13}$ Alternatively, if testing the maximum hypothesis bias (ie, extreme cases: assuming that the patients lost to follow-up survived or died), the conclusions of Kaplan-Meyer analysis remain unchanged.

Poor adherence is usually defined as the use of ventilation for less than 4 hours/day. ${ }^{14}$ We chose to measure and assess adherence as a continuous variable to unmask individual variations in adherence and to maximise statistical power.

Also, all data were reviewed retrospectively. They had been collected in a busy ambulatory clinical environment in which conditions could not be controlled. However, there were very little missing data.

Most deaths occurred at home, and an autopsy was not usually performed. Information on the cause of death was obtained from the funeral homes, family and death certificates.

\section{CONCLUSION}

Our study suggests that failure to adhere to home mechanical ventilation in patients with DM1 who meet the international criteria for this intervention may be associated with increased mortality. In this population, adherence to NIV is poor, multifactorial and varies unpredictably over time, indicating a need for regular follow-up and repeated delivery of information about the benefits of home ventilation. Therapeutic education programmes may improve patient motivation regarding NIV, thereby potentially improving survival. 
Contributors GB, FL and DO designed the study. GB, FL, DO, PL, HP, JCR and $\mathrm{DA}$ followed the patients and collected the data. GB and FL analysed the data, wrote the manuscript and are the guarantors of the paper. All authors critically revised the manuscript, read the final version and approved its submission for publication.

Funding This research received no specific grant from any funding agency in the public, commercial or not-for-profit sectors.

Competing interests None declared.

Patient consent Obtained.

Ethics approval CNIL CCTIRS (No. yK90609496a).

Provenance and peer review Not commissioned; externally peer reviewed.

(c) Article author(s) (or their employer(s) unless otherwise stated in the text of the article) 2018. All rights reserved. No commercial use is permitted unless otherwise expressly granted.

\section{REFERENCES}

1 Harley HG, Walsh KV, Rundle S, et al. Localisation of the myotonic dystrophy locus to 19q13.2-19q13.3 and its relationship to twelve polymorphic loci on 19q. Hum Genet 1991;87:73-80

2 Mathieu J, Allard P, Potvin L, et al. A 10-year study of mortality in a cohort of patients with myotonic dystrophy. Neurology 1999;52:1658-62.

3 Laub M, Berg S, Midgren B. Symptoms, clinical and physiological findings motivating home mechanical ventilation in patients with neuromuscular diseases. J Rehabil Med 2006:38:250-4
4 Annane D, Orlikowski D, Chevret $\mathrm{S}$, et al. Nocturnal mechanical ventilation for chronic hypoventilation in patients with neuromuscular and chest wall disorders. Cochrane Database Syst Rev 2007:CD001941.

5 Boussaïd G, Lofaso F, Santos DB, et al. Factors influencing compliance with noninvasive ventilation at long-term in patients with myotonic dystrophy type $1: \mathrm{A}$ prospective cohort. Neuromuscul Disord 2016;26:666-74.

6 Nugent A-M, Smith IE, Shneerson JM. Domiciliary-assisted ventilation in patients with myotonic dystrophy. Chest 2002;121:459-64.

7 Sanders MH, Kern N. Obstructive sleep apnea treated by independently adjusted inspiratory and expiratory positive airway pressures via nasal mask. Physiologic and clinical implications. Chest 1990;98:317-24.

8 Clinical indications for noninvasive positive pressure ventilation in chronic respiratory failure due to restrictive lung disease, COPD, and nocturnal hypoventilation--a consensus conference report. Chest 1999;116:521-34.

9 Laberge L, Veillette S, Mathieu J, et al. The correlation of CTG repeat length with material and social deprivation in myotonic dystrophy. Clin Genet 2007;71:59-66.

10 Serra L, Silvestri G, Petrucci A, et al. Abnormal functional brain connectivity and personality traits in myotonic dystrophy type 1. JAMA Neurol 2014;71:603-11.

11 Poussel M, Thil C, Kaminsky P, et al. Lack of correlation between the ventilatory response to $\mathrm{CO} 2$ and lung function impairment in myotonic dystrophy patients: evidence for a dysregulation at central level. Neuromuscul Disord 2015;25:403-8.

12 O'Donoghue FJ, Borel JC, Dauvilliers Y, et al. Effects of 1-month withdrawal of ventilatory support in hypercapnic myotonic dystrophy type 1. Respirology 2017;22:1416-22

13 Alberti C, Timsit JF, Chevret S. [Survival analysis: how to manage censored data? The Kaplan-Meier's méthod]. Rev Mal Respir 2005;22(2 Pt 1):333-7.

14 Nugent AM, Smith IE, Shneerson JM. Domiciliary-assisted ventilation in patients with myotonic dystrophy. Chest 2002;121:459-64. 